\title{
Enhancing the Sense of Community Through Interaction in a Global Online Course
}

\author{
Tuulikki Keskitalo \\ Correspondence: Tuulikki Keskitalo, Master's Degree Programme, Lapland University of Applied Sciences, Rovaniemi, \\ Finland.
}

Received: January 5, 2021

doi:10.11114/jets.v9i2.5144
Accepted: January 25, 2021

Online Published: January 26, 2021

URL: https://doi.org/10.11114/jets.v9i2.5144

\begin{abstract}
The purpose of this study was to investigate what types of interactions promote students' sense of community in a global online course. This design-based research study was aimed at finding out practical principles to help students develop a sense of community and have a meaningful learning experience. A total of 82 students participated in the study. Data were collected and analysed using both qualitative and quantitative methods during three design-based research cycles. These analyses produced six qualitatively different categories that were completed with questionnaire data. To meet the goals of the design-based research, this study produced an online higher education course and design principles, as well as deepened our theoretical understanding of the sense of community in online learning.
\end{abstract}

Keywords: sense of community, online learning, design-based research (DBR), mixed method

\section{Introduction}

Online learning has become very popular in the last two decades because of the development of technology and the pressure of educational organisations to meet the needs of individual students and their life circumstances. However, the interaction and sense of community of students are known to be challenging for online courses because of the lack of a natural sense of social presence (e.g. Oliphant \& Branch-Mueller, 2016; Rovai, 2002a; Sung \& Mayer, 2012). The lack of social presence affects the interaction and sense of community of students in online learning environments, which in turn has an impact on the dropout rates in online courses (e.g. Luo, Zhang, \& Qi, 2017; Moore, 2014), and it may also affect their learning achievements (Rovai, 2002a). Therefore, online courses should be carefully planned and facilitated (Shackelford \& Maxwell, 2012; Teng, Chen, Kinshuk, \& Leo, 2012) to support the development of sense of community and persistence with online education.

In this study, a course is presented, which was attended by students from different parts of the country, and the instructor was based on a different continent. This set-up complicated the mode of conducting the course because of the time difference, for example. Because of the challenges involved in online courses and the knowledge that the sense of community and interaction are often considered challenging for online courses; special emphasis was put on these characteristics when planning the course.

The purpose of this study was to examine what type of interactions promote the sense of community of students in a global online course. The study was aimed at finding out how students perceived the interaction during the course and how it helped them develop a sense of community with the team as well as with the whole student group. As this study was based on the design-based research (DBR) method (e.g. Barab \& Squire, 2004), the aim was to develop this specific course further, as well as assist with the development of other similar courses in the future.

This article starts with a brief introduction to previous research on online courses, with a special focus on interaction and sense of community. Then, it presents the research questions and multiple methods that were applied during the study. The article presents the results and discusses them. Finally, it draws conclusions and provides some guidelines and viewpoints to educational practitioners and researchers on where to concentrate in the future.

\section{Theoretical Framework}

\subsection{Previous Studies on Online Education and the Sense of Community}

The sense of community has been studied quite extensively in relation to both classroom (e.g. Tinto, 1997) and online education (e.g. Garrison, 2006; Garrison, Anderson, \& Archer, 2001; Rovai, 2002a; 2002b; Teng, Chen, Kinshuk, \& 
Leo, 2012). According to McMillan and Chavis (1986), the sense of community of students can be defined as their feeling of belonging with the group members, that the group members matter to one another and to the group, and that students also have faith that their needs would be met through commitment to this specific group. According to Rovai (2002a), the most essential elements of the sense of community include mutual interdependence among group members, connectedness, trust, interactivity, and shared values and goals. In this study, the original and widely used definition of sense of community has been applied to online learning (cf. McMillan \& Chavis, 1986): In an online learning environment, the students' sense of community is based on the students'feeling that the group members feel real. Thus, students may develop the feeling of belonging to their online student group. Through their commitment and interaction with this specific group, they also have feeling that the online group members matter to one another and to the online group, and students also have faith that their needs will be met.

As noted, in an online learning environment, social presence also influences the development of sense of community (Richardson, Maeda, Lv, \& Caskurlu, 2017; Sung \& Mayer, 2012). According to Garrison (2006), social presence reflects a student's ability to connect with other students on a personal level, which forms the ground for the development of sense of community. According to Swan et al. (2009), social presence is comprised of affective expression, group cohesion, and open communication. However, according to Garrison (2006), collaborative and constructivist learning experiences are achieved at the intersection of social, cognitive, and teaching presence. In other words, students also need to delve into constructing a joint meaning of the content through collaboration (cognitive presence), and teaching presence is needed to structure and lead the learning process (Garrison, 2006). All of this needs a thoughtful pedagogical design.

The sense of community needs the interaction among students to be able to grow over time (Akyol \& Garrsion, 2008; Cutler, 1996; Garrison, 2006; McClannon, Cheney, Bolt, \& Terry, 2018; Rovai, 2002a). In online learning, the sense of community can be facilitated through many types of interactions, using various features of the learning technology (e.g. Luo et al., 2017; Shackelford \& Maxwell, 2012; Tanis, 2020). Previous studies have categorised the interaction among students in online learning environments into three different categories: (1) learner-learner, (2) learner-content, and (3) learner-instructor (Luo et al., 2017; Moore, 1989). Of these types of interactions, learner-learner and learner-instructor interactions are known to contribute the most to students' sense of community (Luo et al., 2017). So, how does the instructional design help us enhance the interaction among learners, the instructor, and the learning environment, and furthermore, how does it influence the sense of community in a global online course?

The starting point for the development of sense of community is pursuing a safe and respectful climate within a study group (Garrison, 2006), which can be facilitated through pedagogical design. Many studies have shown that if students have the chance to get to know each other, it would contribute to a stronger sense of community during an online course (e.g. Garrison, 2006; Mamonov, Koufaris, \& Benbunan-Fich, 2016; Shackelford \& Maxwell, 2012; Sung \& Mayer, 2012). Some studies also suggested having face-to-face orientation meetings to develop bonding among students (Haythornhwaite, Kazmer, Robins, \& Shoemaker, 2006); however, this is not always possible because of physical distance. According to Stepich and Ertmer (2003), having small-group discussions where students share their backgrounds, previous experiences, and common interests may help students build a stronger sense of community (see also Garrison, 2017; Sung \& Mayer, 2012; Wolcott, 1996), as they help build closer social relationships among course participants (e.g. Sung \& Mayer, 2012).

The sense of community in online courses can also be promoted through learning assignments. The assignments that require collaboration and sharing of information among group members are known to enhance the sense of community (e.g. Rovai, 2002b). Conducting a joint enquiry into the course content and co-constructing the knowledge help build a sense of community through cognitive presence (Garrison, 2006). However, the sense of community tends to usually develop within team members, not with the whole study group (Liu, Magjuka, Bonk, \& Lee, 2007). In this specific course, the students first discussed the case study and made the selection on the basis of their common interest. Thereafter, they worked collaboratively in small groups with the chosen case during the course. As reciprocal teaching (or peer teaching) has been noted to be in relation to the sense of community (Shackelford \& Maxwell, 2012), they were also used as one of the pedagogical methods in this course. The assignment was also divided into smaller steps according to the time available for the course (cf. Garrison, 2006). The idea was to help students construct their understanding and concrete outputs.

As noted, the instructional design and course facilitator are in a key position to develop students' sense of community (cf. Garrison, 2006). The facilitator is responsible for creating and structuring the content, facilitating students' interaction, planning learning assignments, and eventually doing the assessment (Garrison, 2006; Rovai, 2004). All of these can be purposefully designed to increase the interaction among learners, the instructor, and the course material, and furthermore, they may aid the development of sense of community. For example, according to Rovai (2004), the presentation of content on an online platform should be done in multiple intuitive ways to support individual learners. 
The presentation of content may include video presentations, PowerPoint slides, notes from the instructor, additional readings, and so on. Students should also be able to view the content at any time, thus promoting flexibility (Rovai, 2004). Rovai (2004) also suggested that some kind of welcoming page or video may be helpful for creating a sense of community. When facilitating interaction, the discussion platform can be purposefully used to increase communication and decrease the feeling of isolation and loneliness of participants (Liu et al., 2017). According to Rovai (2002a), in online courses, students should be provided with increased affective support in order to promote and sustain a strong sense of community (see also Jiang \& Koo, 2020). For example, in this specific course, there were voluntary meetings with the instructor available for students. However, students were also advised to contact the instructor if they had more serious or sensitive topics they would like discussed privately.

\subsection{Pedagogical Design Framework of the Present Study}

As noted, a proper instructional design may enhance the sense of community and positive online learning experiences of students (e.g. Rovai, 2004; Shackelford \& Maxwell, 2012; Teng et al., 2012). This study's overall pedagogical framework is based on Lonka's (2015) phenomenon-based learning model. The model is based on our current understanding of learning. It consists of three phases: (1) starting the learning process, (2) guiding and supporting the learning process, and (3) conducting an assessment. In the first phase, the most important thing to do is activate the previous knowledge and experiences and diagnose the learning needs. After the first phase, students should have formed the initial learning goals. The second phase includes collaborative and self-directed learning, and the facilitator's main task is to provide support and facilitate students' learning. The third phase includes a critical reflection of the achievements and learning process, that is, asking questions such as "What have we learnt?", and "How was the learning process?" According to Lonka (2015), the model can be applied to many types of instructions, including 1-hour lessons, or to more comprehensive and long-lasting courses. In this study, the model was applied to a global online course that lasted from 4 to 10 weeks.

In addition to the phenomenon-based learning model, case-based teaching formed the basis of learning assignments. According to Irby (1994), there are five principles that describe case-based teaching: (1) anchoring the instruction to real life, (2) active participation of students, (3) modelling expert reasoning, (4) facilitation and feedback, and (5) supporting the learning environment. In this particular course, the students were advised to choose the real-life case which they could use as a real-life example and draw conclusions from. To be able to deeply understand the case and chosen phenomenon, they were also advised to, for example, interview the case participants, thus featuring expert modelling. The students were also responsible for finding the necessary information by themselves that would help them analyse and understand the chosen case. The instructor's main role was to facilitate the learning process and interaction of students.

\section{Research Question}

The following research question was set for the study: "How can the sense of community be enhanced in a global online course?"

\section{Design-Based Research as an Overall Methodology}

The overall framework of the study is DBR methodology, where designs are formed in continuous cycles of design, implementation, analysis, and redesign phases (Barab \& Squire, 2004; Design-Based Research Collective, 2003). This study was aimed at designing a global online course to provide students with a learning environment where they are able to feel themselves present and develop a sense of community with their online student group. In the end, this DBR project would produce new knowledge about the interaction and sense of community, as well as design principles that can be used to design and conduct future global online courses within the higher education context. The study consisted of three iterative cycles that were introduced next in addition to course content, context, and data collection and analysis methods. These three DBR cycles took place between fall 2019 and spring 2020.

\subsection{Course Content}

The course content was about autonomous and self-directed teamwork. The course was aimed at students to master, after completing the course, the ground principles of autonomous teams and specific characteristics of managing these kinds of teams. After the course, students should also know the principles of diversity in recruiting and how this way of organising the work may increase creativity, among other things.

In all three courses, as a learning assignment, the students needed to complete the case study analysis about the chosen real-life case. In this case, they could choose a real-life case from their own background organisations or some other organisation they knew that used teamwork. In the first and second cycles, the case study analysis consisted of three different phases: First, the students needed to create the audiovisual (AV) presentations of knowledge acquisition that supported the formation of theoretical background of the case studies. Thereafter, they completed their case study 
reports in written format where they could utilise the gained theoretical background and data collection (e.g. interviews with experts in working life). The final phase of the learning assignment was to present their results at a webinar. However, after the webinar, the students also had an opportunity to finalise the case study reports in accordance with the peer review feedback they received at the final webinar. In the third cycle, the learning assignment was divided into two phases: (1) writing the joint case study report and (2) presenting the results in the final webinar. In this course, the first phase was left out because the students needed to complete the course in a shorter time period.

These learning assignments were completed in a group of five students. The purpose of the group assignment was that the students could apply the principles of autonomy and self-directedness in their own teamwork. Because of the physical distance, they also employed digital tools - such as Microsoft Teams, Skype, or WhatsApp —in their social collaboration. The collaboration was not restricted to any particular digital tool, but rather they could choose the ones that best suited their needs. However, they could also use the course's Adobe Connect Pro (ACP) lecture room. It was also expected that the students would reflect on their own teamwork process and its development in the case study reports. Basically, there were two kinds of analyses: (1) analysis of the chosen case and (2) analysis of the team's own teamwork and collaboration.

\subsection{Research Context}

In all the courses, the online study platform Moodle was used as a main tool for communication. Moodle can be used for sharing course content and material and returning the learning assignment, but it also has many other features. For example, it allows you to have asynchronous discussions with other students and the instructor through a discussion platform. ACP was used for synchronous communication. In this course, ACP could be accessed through Moodle. However, the students could also install the ACP application on their mobile phones and use the mobile ACP application to access synchronous course meetings. ACP also has many features. In this course, it was used to orient students to the course, host instruction meetings with the instructor, and organise the last meeting (online webinar) during which the students shared the results of their case reports.

Two of the courses (first and second cycles) started a week before the actual course with students' presentations on Moodle's discussion platform. The second course (second cycle) also included the voluntary testing of digital tools, which happened a day before the orientation meeting. After voluntary presentation and testing, all the courses had orientation meetings that lasted 3 hours. During orientation, the instructor shared the presentation with the participants and told them what the course was about, how it was organised, what the pedagogical grounding was, and what the learning assignments were. This phase took approximately an hour. Thereafter, the students could freely choose their teams using one of the features offered by Moodle. Each group had approximately five participants. The instructor divided the whole group into smaller teams on the basis of their own selection. After the distribution, the students started planning their learning assignments as a team. During group work, the students were advised to discuss who they were, what skills and expertise each team member had, what could be the possible case, and what could be the possible viewpoint that the case was examined from? However, it was also advised that they continued the discussion afterwards on the platform that better suited them and that they decided the platforms for communicating within the team.

After orientation meetings, the students continued their work in teams. However, the instruction was provided to them through optional instruction hours via ACP. This way of providing instruction was chosen because in self-directed teamwork, teams work quite independently and the leader is more like a coach or facilitator. In this course, the teacher's main role was to act more like a facilitator of the learning and collaboration of the students. During the course, the students sought information independently, but the course also included four lectures about the topic. The lectures were available in Moodle, and the students could view these lectures at any time that was most suitable for them.

\subsection{Description of the Three Cycles and the Participants}

\subsubsection{First Cycle}

The first DBR cycle was conducted in the autumn of 2019. The participants in the first cycle included 25 master's degree students from seven different Finnish Universities of Applied Sciences in different parts of the country, and the instructor was based in the United States. Of these students, 19 were females and 6 were males. In addition, the students represented four different study fields, including health care, services, business, and economics, as well as industry and engineering. The course lasted 10 weeks.

\subsubsection{Second Cycle}

In the second DBR cycle, the participants included 27 master's degree students from 11 different Finnish Universities of Applied Sciences in different parts of the country, and the instructor was working from the United States. Of these students, 24 were females and 3 were males. The students were from social, health care, business, and economics sectors. Their course also lasted 10 weeks. 


\subsubsection{Third Cycle}

In the third cycle, there were 32 (21 female and 11 male) master's degree students from one Finnish University of Applied Sciences. Again, the instructor was based on a different continent. These students represented themselves in four different study fields, including business and economics, agriculture and forestry, services and industry, and engineering. This course lasted 4 weeks, which is why their learning assignment was adjusted to better meet their timetable.

\subsection{Data Collection and Analysis Methods}

The research data collected and analysed during the course of this study are presented in Table 1.

Table 1. Research methods

\begin{tabular}{|c|c|c|}
\hline Research Data & Analysis Method & $n$ \\
\hline \multicolumn{3}{|l|}{ First Cycle } \\
\hline 5 final case reports & Qualitative content analysis & 25 \\
\hline $\begin{array}{l}25 \text { students' } \\
\text { self-evaluation forms }\end{array}$ & Qualitative content analysis & 25 \\
\hline Feedback questionnaires & $\begin{array}{l}\text { Quantitative analysis methods (mainly descriptive } \\
\text { statistics) }\end{array}$ & 7 \\
\hline $\begin{array}{l}\text { Discussions on Moodle's } \\
\text { discussion platform }\end{array}$ & Qualitative content analysis & 25 \\
\hline \multicolumn{3}{|l|}{ Second Cycle } \\
\hline 7 final case reports & Qualitative content analysis & 27 \\
\hline $\begin{array}{l}27 \text { students' } \\
\text { self-evaluation forms }\end{array}$ & Qualitative content analysis & 27 \\
\hline Feedback questionnaires & $\begin{array}{l}\text { Quantitative analysis methods (descriptive } \\
\text { statistics) }\end{array}$ & 6 \\
\hline $\begin{array}{l}\text { Discussions on Moodle's } \\
\text { discussion platform }\end{array}$ & Qualitative content analysis & 27 \\
\hline \multicolumn{3}{|l|}{ Third Cycle } \\
\hline 6 final case reports & Qualitative content analysis & 32 \\
\hline $\begin{array}{l}32 \text { students' } \\
\text { self-evaluation forms }\end{array}$ & Qualitative content analysis & 32 \\
\hline Feedback questionnaires & $\begin{array}{l}\text { Quantitative analysis methods (descriptive } \\
\text { statistics) }\end{array}$ & 10 \\
\hline $\begin{array}{l}\text { Discussions on Moodle's } \\
\text { discussion platform }\end{array}$ & Qualitative content analysis & 32 \\
\hline \multicolumn{3}{|l|}{ Total } \\
\hline \multicolumn{3}{|c|}{ Students, $N=84$ (64 females, 20 males) } \\
\hline \multicolumn{3}{|l|}{ Final case reports, $N=18$} \\
\hline \multicolumn{3}{|c|}{ Students' self-evaluation forms, $N=84$} \\
\hline \multicolumn{3}{|c|}{ Feedback questionnaires, $n=23$ (response rate $27.38 \%$ ) } \\
\hline
\end{tabular}

Students' learning assignments included AV presentations of the theoretical framework (first and second cycles), written case study reports, and final AV presentations of the case study reports. Out of these assignments, the case study reports in progress were returned 1 week before the final online webinar. The purpose of the early return was that the other team could be given enough time to conduct peer review of the work in progress and provide constructive feedback in the final webinar. The final written case study reports were returned a week after the final webinar. The case study 
reports in progress were polished in accordance with the peer review in the final webinar. One week after the seminar, students' individual and peer evaluation forms were also returned. In these forms, the students provided feedback to their team members about the collaborative learning process and reflected on their own performance. They were also advised to grade their team members, as well as grade their own performance. Approximately 1 week after the course was completed, the students received summaries of their peer review feedback, which was gathered by the instructor and sent via individual email messages. This specific email message also consisted of a link to the online feedback survey about the course that queried the students about their experience of the collaboration methods and sense of community. The questionnaire included 10 questions with one background question (e.g. "My study field is"). The questions such as "I felt I was part of the whole student group" were evaluated on a five-point Likert scale $(1=$ disagree, $\ldots, 5=$ agree). A total of 23 students responded to the survey. The special focus in the analysis was on students' ways of interaction and sense of community. Therefore, discussions on Moodle's discussion platform were also analysed and reported. Altogether, the data included 615 pages of written documents by the students.

In this study, the final case study reports, students' self and peer evaluation forms, and discussions on Moodle's discussion platform were analysed using qualitative content analysis (e.g. Graneheim \& Lundman, 2004). The analysis was inductive in nature. In inductive analysis processes, the starting point is the data, rather than the theoretical analysis framework that is decided beforehand. During this specific analysis process, the data were read as a whole many time. At the same time, sentences were underlined that somehow depicted the phenomenon under investigation. Thus, the meaning unit in this study was one to three sentences (e.g. "the team experienced a strong social and task-focused sense of community and sense of belonging"). This phase resulted in 60 sub-categories. Thereafter, the underlined meaning units were categorised on the basis of the similarities and differences (e.g. differences in working styles). This phase was iterative in nature and needed close reading of the meaning units and data. This resulted in 30 sub-categories. Following this, these 30 categories were carefully studied and compared with the theory and data. Finally, six categories were formed that helped answer the research question of this study, which included (1) being committed to teamwork and to a shared goal; (2) trust as a base for the sense of community; (3) being aware of and open to different working styles; (4) distributing work mindfully, as it may diminish communication; (5) valuing constructive, open, and regular communication; and (6) facilitating students' learning. In the Results section, these six categories are presented in a synthesis with analysis of the questionnaires. The questionnaires were analysed using descriptive statistics because of the low response rate $(27.38 \%)$.

\section{Results}

Each of the design cycles is reported separately to highlight the implications that every cycle had on the next design.

\subsection{First Design Cycle-Testing the Initial Course Design}

On the basis of the final case reports and students' evaluation of their own teamwork, many teams had common goals which formed the basis for their teamwork and sense of community (Rovai, 2002a), as the following teams described:

"Making this assignment has been really interesting. We found the case directly from one of our team members' workplace, and it is very topical". (Final case report 2)

"According to the definition of the real team, we were a small group of people, who had a common goal ...". (Final case report 1)

As previous studies have shown, students mainly interact with team members (cf. Liu et al., 2007), which also happened in this course. However, analysis of the questionnaires revealed that there is only little difference between the development of community with the whole group and with their team members, as the statements "I felt I was a member of our team" (mean $[M]=4.7$; standard deviation $[S D]=0.49$ ) and "I felt I was part of the course's study group" $(M=4.0 ; S D=1.15)$ unveiled. The students $(n=7)$ who answered the questionnaire also thought that the discussion with the team members helped them learn $(M=4.6 ; S D=0.53)$. However, one student mentioned that he would have liked to have more interaction with other students as well:

"I would have like that during the course we would have more opportunities to discuss with the other students about team-work and get new viewpoints also from them". (Questionnaire 1)

This is tricky because in the course's discussion platform, the students were encouraged to have discussions about the course topic. However, after their presentation, only two wrote on the discussion platform. These two writings also concentrated on the challenges with technology and not because they wanted to discuss the course topic. So, it seems that without the facilitator's interference and initiative, the students were not willing to start the discussion on their own. Rovai (2003) also noticed that grading strategy significantly influenced the discussion, which in turn had an impact on students' sense of community. In this course, the discussion was voluntary and not graded.

The team that received the best grades from the course had a good atmosphere and effective communication among the 
team members. They had also conducted a thoughtful reflection of their own teamwork compared to other teams. Other teams had mainly described the teamwork in two paragraphs, whereas this team also took advantage of the theoretical knowledge gained during this course in their effort to understand the teamwork and reasons for the good atmosphere, effective communication, and great achievements. On the basis of the reflection on their own teamwork, successful teams had 10 Skype meetings during the whole course. The team communicated via WhatsApp and emails in between the synchronous meetings. They used Google Docs and Teams to share documents. On the basis of their own reflections, the team described their teamwork as follows:

"Our team-work towards each other was encouraging, supporting and insightful .... We think we were top team, because we support each other, and we think everybody got additional value from our team-work besides the own expertise. We were more than sum of its parts. It was because we met often, but efficiently, and we had a clear goal". (Final case report 1)

"Our whole team worked together unbelievable well during the whole course. We met often and regularly, and everybody worked as much .... It was a pleasure to work with this self-directed and autonomic team!" (Student self-evaluation 17)

The sense of community in online courses can be best promoted through collaborative learning assignments (e.g. Rovai, 2002b). Therefore, for the learning assignment, a small-scale case-based study was chosen so that the students could collaborate in groups of five students each. In these assignments, the students were required to analyse not only the particular case but also their own teamwork. Those who answered the questionnaire thought that the assignment was quite motivating $(M=3.4 ; S D=0.98)$ and that the collaborative learning assignment supported their learning $(M=4.6$; $S D=0.90$ ). However, some teams struggled to gain understanding of the assignment, as this particular team described:

"The instructions were sometimes unclear and I would have needed corrections to assignments (for example, the audio-visual presentation was understood very differently among the course members)". (Questionnaire 4)

Online learning can be challenging; thus, extra support was available for them (cf. Rovai, 2002a). In addition to peer support and Moodle's discussion platform, the students were provided with six instruction meetings during the course. They could choose to participate in these meetings if they felt they needed to talk to the instructor. In addition to these meetings, they could send emails to the instructor. Altogether, three teams took advantage of having extra guidance and support. Interestingly, the team that struggled the most and received the lowest grade from the course did not seek support, although they would have benefited from that, as their own description tells us:

"The assignment and instruction were very much in the 'grey area' for us; that is, we did not understand the whole idea and assignment". (Final case report 4)

All in all, the students who answered the questionnaire thought that there was enough guidance available $(M=3.8 ; S D$ $=0.69)$; they also felt that there was enough support available for taking this course $(M=3.6 ; S=0.98)$. However, one student also suggested in the questionnaire that instruction should be mandatory, as some teams clearly had difficulty in understanding the assignment:

"Should the instruction meetings be 'mandatory'so that we can avoid misunderstandings?" (Questionnaire 5)

In the course, web cameras and facilitator's video feedback were exploited as ways to increase the feeling of social presence and, thus, the sense of community (Sung \& Mayer, 201). According to the students, web cameras somewhat increased the feeling of social presence in teaching $(M=3.3 ; S D=1.7)$, although there was a lot of variation in their answers. They also felt that video feedback supported their learning at some level $(M=3.3 ; S D=1.3)$.

On the basis of these findings, the following modifications were made to the next course: (1) more instruction meetings were provided to the students, and during the orientation meeting, it was emphasised that these were highly recommended; (2) extra effort was also put in explaining the learning assignment (including the instruction that the written assignment could be found on Moodle, and the assignment was also explained to the students during the orientation meeting), although it was mentioned that the assignment should not be too straightforward; (3) during the orientation meeting, although the students had their small-group discussion, they were also encouraged to have informal discussion with each other in order to form a social bond and enhance their sense of community - for example, they were encouraged to share something personal about themselves; (4) for the next course, a short additional meeting was also provided to the students before the actual orientation meeting. In this half-hour voluntary meeting, the students could explore ACP and the connections beforehand. The purpose of all this was not only to aid their learning, but also to support their collaboration and enhance the sense of community. All in all, the initial course design formed a good starting point for developing the global online course further in a project that aimed to enhance students' sense of community. 


\subsection{Second Design Cycle-Adjusting the Learners'and Teachers'Needs}

On the basis of the data collected during the second cycle, the participants in the second course seemed to be in a situation similar to that in a previous course. The course assignment was a motivating starting point for collaboration, as the final case report revealed:

"Collaboration started in a good spirit and we all were motivated to work on the assignment.... We are pretty sure that collaboration was easy because we were able to find a case that everybody was interested in". (Final case report 7)

The questionnaire also revealed that the students viewed learning assignments as motivating $(M=4.67 ; S D=0.52)$. However, some teams also stated that they had a more practical orientation towards the course:

"We were connected, because we had a common goal for learning something new, pass the course and finally, to graduate, which formed the purpose and impact for our work". (Final case report 11)

In this course, the discussion platform was also used mainly as a means to communicate with the instructor about common things related to the course-for example, to clarify instructions related to the peer review process or notify that the folder where the final case reports should have been returned did not work properly. The questionnaire also revealed that the discussion platform was not so meaningful for students' learning $(M=3.33 ; S D=0.52)$. It seems that the teams communicated with their own team members rather than the participants in the whole course. However, interestingly, the questionnaire revealed that the students felt that they belonged to the whole group $(M=4.83 ; S D=$ $0.41)$ more than they did to their team $(M=4.67 ; S D=0.82)$.

On the basis of this analysis, it seems that the teams that enjoyed working together shared a common goal and mutual feeling of trust. They were also committed to the course and teamwork. In these teams, the workload was also evenly distributed, and the team members offered help to each other. These teams also met regularly. One team also consciously took advantage of emotional expressions with emojis (cf. social presence, Teng et al., 2012; Swan et al., 2009). It seems that these teams were able to create a climate of mutual trust and belonging, which - according to Garrison (2006) - facilitated upcoming interactions. This is how the teams described their teamwork:

"All in all, group work was successful, because everybody gave input to the assignment and we had regular online meetings". (Final case report 9)

"Everybody had a feeling of good team work and team spirit as well as feeling of trust to other team members". (Final case report 10)

The interaction and sense of community of some teams were disrupted by differences in their motivation and working styles. On the contrary, motivation seemed dependent on the life circumstances of the individual learner. One team in particular was drawn into disagreements. However, they were able to put together a good final case report, but the self-evaluation forms revealed that they struggled as a team:

"In the most difficult times, I doubted that, were the half of our group 'fake students', and purpose of the group is to put students together in order to manage challenging team work situations.... After all, I believe that this was not intentional, but rather I got a team where we did not get communication go along, and our working styles were very different". (Self-evaluation form 46)

Two of the teams did not particularly struggle, but they were not able to build a strong sense of community, which they thought was because they did not meet so often. It seems that they initially divided the tasks in order to work alone on a separate task, rather than collaboratively co-constructing the same case report. This minimised the need for interaction, which is essential in building a sense of community (e.g. Garrison, 2006). The students described the situation as follows:

"We shared assignments right away in a first conference call pretty precisely, which partly lessened the need to be in contact with each other". (Self-evaluation form 44)

"We could have put more effort on communication within a team. We communicated only occasionally since we gave up the conference calls". (Final case report 8)

Despite challenges, the teams did not take advantage of instruction meetings related to teamwork per se. The questionnaire also revealed that the students thought that there was enough guidance available $(M=4.83 ; S D=0.41)$ and also that there was enough support available for taking this course $(M=4.83 ; S D=0.41)$. Learning assignments revealed that the students were aware of the challenges, but they thought that they would manage through the course because it was "only a school assignment":

"I did not think it was necessary to go through these things, because it was only a course". (Self-evaluation form 31)

"When working was initially impractical, it was not easy or natural to discuss, for example, negative issues. We 
experienced responsibility that we should keep the challenging work climate positive and as fluent as possible. For example, in communication we tried to focus on keeping up the positive climate, clarity as well as concrete suggestion of how to improve the work". (Final case report 11)

In this group, the students felt that web cameras supported their sense of community during this course to a great extent $(M=4.67 ; S D=0.52)$. On the basis of these findings, only minor modifications were made to the next implementation. The next course was also slightly different, which made it necessary to modify the course for this student group.

\subsection{Third Design Cycle — Finalising the Design and Forming the Design Principles}

The starting point for the third cycle was somewhat different from that for previous courses. In this course, the instructor was aware that the majority of students knew each other from previous courses and that they were familiar with this type of case-based learning assignment as well. The timeline for the course was also shorter, which is why the students did not produce any AV presentation as a learning assignment. They proceeded straight to working on the written final case reports.

The easiness and fluency of students' collaboration depicted the atmosphere of this course very well. The reason for this might be that the students already knew each other, as these teams wrote:

"Almost all the team members had previous experiences on working together from previous courses, so we had acknowledged the differences in personalities and working styles of each team member". (Final case report 14)

On the basis of analysis of the questionnaires, the students felt that they belonged to the whole group $(M=4.60 ; S D=$ $0.96)$, but they were also part of the team $(M=4.70 ; S D=0.95)$. As we also expected, they were familiar with the case-based teaching approach as well, and the learning assignment seemed clear for most of them, as this case report revealed:

"We had a clear understanding about the goal and commitment, on the one hand, due to the clear instructions on the learning assignment, but on the other hand, because all the team members wanted to achieve the same things: learning, study points and on a long term, degree". (Final case report 13)

The questionnaire also revealed that collaborative learning assignments were motivating $(M=4.40 ; S D=0.70)$, supported the accomplishment of the course $(M=4.40 ; S D=0.70)$, and supported the learning of the content $(M=4.50$; $S D=0.53$ ). On the basis of the analysis, the majority of teams also seemed to have clear goals and a joint vision on how to proceed. Many teams had also divided the tasks in the beginning, which took the learning assignment forward. However, according to the analysis, this also seemed to diminish the need for collaboration, as was the case in previous course. Furthermore, this affected the quality of the learning assignment in some teams, as the following student described:

"Synthesis was at a pretty low level, and you can see from the work how the group was committed to this work". (Student 78)

The learning assignment was designed to be produced in close collaboration with the students, where the idea was to take advantage of each other's skills and knowledge in order to produce something they would not be capable of doing alone. However, this is pretty often the case when students divide the work and work separately on the same task, but as you can see, this is not always ideal.

Technology can also be harnessed to enhance students' learning experience in an online learning environment (cf. Luo et al., 2017; Moore, 1989). In this particular course, the students felt that web cameras supported their sense of community during the course $(M=4.70 ; S D=0.48)$, whereas the discussion platform did so only moderately $(M=3.80$; $S D=1.62)$.

\section{Discussion}

On the one hand, the starting point for the development of the course was that the difficult, global pandemic forced many educational organisations into online education and, on the other, the knowledge that the sense of community may be difficult to achieve, as the interaction is affected by the lack of a natural sense of presence (e.g. Oliphant \& Branch-Mueller, 2016; Rovai, 2002a; Sung \& Mayer, 2012). Thus, the main goal of this DBR study was to find ways to support the interaction among students in a global higher education online course in order to enhance their sense of community. On the basis of data analysis, it can be said that the sense of community in online higher education can grow and blossom if students are committed to teamwork and to a shared goal. Through progress as well as constructive, open, and regular communication, students are also able to form feelings of trust, which forms a base for the sense of community. To strengthen the sense of community, being aware of and open to different working styles is essential. Students should also be mindful when distributing the work, as it may make them a loner and weaken the learning results. Facilitation of students' learning is also necessary. 
This study has many similarities to previous research. First of all, the study confirmed that the sense of community takes time to grow (cf. Garrison, 2006; Richardson et al., 2017). For example, in the last course, the atmosphere was relaxed and the students found it easy to get to work because they had known each other for almost a year. So, it seems that this special student group had a feeling that the peer students were real and that they belonged to this group too. On the basis of their previous experiences, they knew that they could also count on these students and achieve the shared goals (cf. McMillan \& Chavis, 1986). Interestingly, there were also teams that had a strong belonging and sense of community despite the shorter familiarisation time. These teams also produced high-quality products. So, it became evident that there might be secret ingredients other than time which affect the sense of community in a higher education online course (cf. Richardson et al., 2017).

This study also confirmed Liu et al.'s (2007) finding that a sense of community is usually built with the closest team members. In this study, the students felt they belonged to both groups; however, the interaction was much more active within the small group than with the whole online study group. The learning assignment required a great deal of collaboration and interaction with the team members; thus, the instructional design clearly promoted the interaction. This study also confirmed that the success of interaction among group members often determines the quality of final solutions (e.g. Thompson \& Ku, 2010). This was also the case in this study. On the one hand, the team that received the highest grade also had the most profound reflection of their own teamwork and most effective teamwork: Their working climate was respectful and they also met often. On the other hand, the teams that made the decision to divide the assignment into separate tasks and work mostly separately were not able to produce high-quality case study reports. As noted, the intensity and regularity of communication might have had an impact on students' sense of community.

In the first two courses, some students complained about the unclear learning assignments. However, the purpose of these learning assignments was also not to provide students with too straight instructions, as their task was to communicate within the team to deal with the real-life case, which can sometimes be wicked. However, the successful team also seemed to enjoy the task, as they collaborated to solve the problem and could use their creativity and exploit previous experiences during the learning process. Previous experiences with the case-based teaching method seemed to also help in adjusting to the learning assignment.

In the course, there was also additional affective and cognitive support available for students, as suggested by previous studies (Rovai, 2002a). However, it was voluntary, and those teams that would have benefited from it most did not use the opportunity. The discussion platform was also used as a means to communicate with the students and other learners, but on the basis of the analysis, it seems that the teacher's encouragement was not enough to get the students to be active on this platform. According to Rovai (2003), grading the discussion is one way to get students to be active and interact, which may also influence their sense of community, but not necessarily their performance (cf. Davies \& Graff, 2005).

Every study also has limitations. The major deficiency of this study was that only 23 students answered the post-course questionnaire. In addition, the learning assignments were not specifically designed to measure the sense of community, so they are not a perfect indicator of the phenomenon. However, this study clearly confirmed that a proper pedagogical design is the key to interaction and building a sense of community among students. This DBR project was started at the same time as the course. The purpose was not only to design a functional course, but also to deepen our theoretical understanding of the sense of community (Barab \& Squire, 2004). The theory-based design might be the reason why the initial design proved to be pretty functional at the beginning, and only minor modifications were made on the basis of the implementation and analysis. Getting to know the theory and known flaws of online learning helped us design an online course that supported the learning of higher education students.

Despite the deficiency, this study is exceptional, as designs were usually tested within a single DBR cycle and did not clearly specify how the revisions were made to the redesign (Zheng, 2015). In this study, the instructor-designer put extra effort into explaining the revisions made to the follow-up design, as it helped in applying them in real life. This supports the two-fold goal of the DBR projects, which is developing the practice and the theory (Barab \& Squire, 2004). However, some of the revisions are hard to describe in a detailed fashion because they are something that plays out in meetings with students (such as using a specific tone to stress the importance of some topic or using bold text in presentations).

However, all of this also raised some interesting further questions. According to Richardson et al. (2017), time affects the magnitude of social presence and, furthermore, the sense of community. However, in this course, there were teams that were able to form a strong sense of community in a shorter time. This warrants more research on the variables that might have an effect on the sense of community in a higher education online course. For example, the intensity and regularity of communication may have an effect on students' sense of community, but also the quality of the interaction may play an important role (Davies \& Graff, 2005). In addition, there seem to be differences in how the learning 
assignment was understood and whether the students sought help or not. Understanding these issues more thoroughly would help us design courses that would better meet the needs of the individual learner. With a wider population, it would also be ideal to investigate whether or not using web cameras and video feedback has an impact on students' feelings of social presence and sense of community. On the basis of this study, it seems that there are individual differences in how the use of technology affects the feeling of social presence and sense of community (cf. Kauffman, 2015).

\section{Conclusion}

Continuous designing, implementation, analysis, and redesign phases during this research project also led to practical design principles that would help practitioners in designing and implementing similar courses in the future. The design principles developed during the course of this study are as follows, which reflect the main findings of this study:

1. Encourage students to discuss their motivation for taking the course, personal working styles, and life circumstances. Being open to one's personal working style and restrictions may help one avoid serious conflicts.

2. Encourage students to work collaboratively, rather than separately.

3. Encourage constructive, open, and regular communication.

4. Provide students with clear instructions on learning assignments.

5. Make sure students understand what is expected of them because they might not be familiar with these types of assignments.

6. Make sure students know who to contact if they struggle with learning assignments.

7. If you want students to have conversation on a discussion platform, that should be clearly instructed or be part of learning assignments.

8. Web cameras or video feedback might have an effect on students' sense of community, so that might be a valuable asset for the global course, where the majority of communication is text based.

To meet the goals of the DBR, this study produced an online higher education course and design principles, as well as deepened our theoretical understanding of the sense of community in an online learning environment. It seems that education always requires walking on a tightrope (cf. Garrison, 2006) between the learning goals and the expectations and needs of the individual learner. However, with proper pedagogical design and facilitation of students' learning, we might have an impact on students' sense of community and, finally, the learning outcomes

\section{Acknowledgements}

I would like to thank the Master's Degree students of Finnish Universities of Applied Sciences who voluntarily take part to this study.

\section{References}

Akyol, Z., \& Garrison, D. R. (2008). The development of a community of inquiry over time in an online course: Understanding the progression and integration of social, cognitive and teaching presence. Journal of Asynchronous Learning Networks, 12(3), 3e22. https://doi.org/10.24059/olj.v12i3.66

Barab, S., \& Squire, K. (2004). Design-based research: Putting a stake in the ground. The Journal of the Learning Sciences, 13(1), 1-14. https://doi.org/10.1207/s15327809jls1301_1

Cutler, R. H. (1995). Distributed presence and community in cyberspace. Interpersonal communication and technology: A Journal for the $21^{\text {st }}$ Century, 1(2).

Davies, J., \& Graff, M. (2005). Performance in e-learning: online participation and student grades. British Journal of Educational Technology, 36(4), 657-663. https://doi.org/10.1111/j.1467-8535.2005.00542.x

Design-based Research Collective. (2003). Design-based Research: An emerging paradigm for educational inquiry. Educational Research, 32, 5-8. https://doi.org/10.3102/0013189X032001005

Garrison, D. R. (2006). Online collaboration principles. Journal of Asynchronous Learning Networks, 10(1), 25-34. https://doi.org/10.24059/olj.v10i1.1768

Garrison, D. R. (2017). E-Learning in the 21st Century: A Community of Inquiry Framework for Research and Practice (3rd Edition). London: Routledge/Taylor and Francis. https://doi.org/10.4324/9781315667263

Garrison, D. R., Anderson, T., \& Archer, W. (2001). Critical thinking, cognitive presence, and computer conferencing in distance education. American Journal of Distance Education, 15(1), 7-23. 
https://doi.org/10.1080/08923640109527071

Graneheim, U. H., \& Lundman, B. (2004). Qualitative content analysis in nursing research: Concepts, procedures and measures to achieve trustworthiness. Nurse Education Today, 24, 105-112.

https://doi.org/10.1016/j.nedt.2003.10.001

Haythornhwaite, C., Kazmer, M. M., Robins, J., \& Shoemaker, S. (2006). Community development among distance learners: Temporal and technological dimensions. Journal of Computer-Mediated Communication, 6(1). https://doi.org/10.1111/j.1083-6101.2000.tb00114.x

Irby, D. M. (1994). Three Exemplary Models of Case-based Teaching. Academic Medicine, 69(12), 947-953. https://doi.org/10.1097/00001888-199412000-00003

Jiang, M., \& Koo, K. (2020). Emotional presence in building an online learning community among non-traditional graduate students. Online Learning, 24(2), 93-111. https://doi.org/10.24059/olj.v24i4.2307

Kauffman, H. (2015). A review of predictive factors of student success in and satisfaction with online learning. Research in Learning Technology, 23. https://doi.org/10.3402/rlt.v23.26507

Liu, X., Magjuka R., Bonk, C., \& Lee, S. (2007). Does sense of community matter? An examination of participants' perceptions of building learning communities in online courses. Quarterly Review of Distance Education, 8, 9-24.

Lonka, K. (2015). Oivaltava oppiminen [Phenomenal Learning]. Helsinki: Otava.

Luo, N., Zhang, M., \& Qi, D. (2017). Effects of different interactions on students' sense of community in e-learning environment. Computers \& Education, 115, 153-160. https://doi.org/10.1016/j.compedu.2017.08.006

Mamonov, S., Koufaris, M., \& Benbunan-Fich, R. (2016). The role of the sense of community in the sustainability of social network sites. International Journal of Electronic Commerce, 20(4), 470-498. https://doi.org/10.1080/10864415.2016.1171974

McClannon, T. W., Cheney, A. W., Bolt, L. L., \& Terry, K. P. (2018). Predicting sense of presence and sense of community in immersive online learning environments. Online Learning, 22(4), 141-159. https://doi.org/10.24059/olj.v22i4.1510

McMillan, D. W., \& Chavis, D. M. (1986). Sense of community: A definition and theory. Journal of Community Psychology, Psychological Sense of Community, I: Theory and Concepts, 14(1), 115-122. https://doi.org/10.1002/1520-6629(198601)14:1<6::AID-JCOP2290140103>3.0.CO;2-I

Moore, M. (1989). Editorial: Three types of interaction. American Journal of Distance Education, 3(2), 1-7. https://doi.org/10.1080/08923648909526659

Moore, R. (2014). Importance of developing the community in distance education courses. TechTrends: Linking Research \& Practice to Improve Learning, 58(2), 20-24. https://doi.org/10.1007/s11528-014-0733-x

Oliphant, T., \& Branch-Mueller, J. (2016). Developing a sense of community and the online student experience. Education for Information, 32, 307-321. https://doi.org/10.3233/EFI-160979

Richardson, J. C., Maeda, Y., Lv, J., \& Caskurlu, S. (2017). Social presence in relation to students' satisfaction and learning in online environment: A meta-analysis. Computers in Human Behaviour, 71, 402-417. https://doi.org/10.1016/j.chb.2017.02.001

Rovai, A. P. (2002a). Sense of community, perceived cognitive learning, and persistence in asynchronous learning networks. The Internet and Higher Education, 5(4), 319-332. https://doi.org/10.1016/S1096-7516(02)00130-6

Rovai, A. P. (2002b). Building sense of community at a distance: A case study. International Review of Research in Open and Distance Learning, 3(1). https://doi.org/10.19173/irrodl.v3i1.79

Rovai, A. P. (2003). Strategies for grading online discussions: Effects on discussions and classroom community in Internet-based university courses. Journal of Computing in Higher Education, 15(1), 89-107. https://doi.org/10.1007/BF02940854

Rovai, A. P. (2004). A constructivist approach to online college learning. Internet and Higher Education, 7, 79-93. https://doi.org/10.1016/j.iheduc.2003.10.002

Shackelford, J. L., \& Maxwell, M. (2012). Sense of community in graduate online education: Contribution of learner to learner interaction. The International Review of Research in Open and Distance Learning, 13(4), 228-249. https://doi.org/10.19173/irrodl.v13i4.1339

Stepich, D. A., \& Ertmer, P. A. (2003). Building community as a critical element of online course design. Educational 
Technology, 43(5), 33-43.

Sung, E., \& Mayer, R. E. (2012). Five facets of social presence in online distance education. Computers in Human Behaviour, 28, 1738-1747. https://doi.org/10.1016/j.chb.2012.04.014

Swan, K., Garrison, D. R., \& Richardson, J. (2009). A constructivist approach to online learning: The Community of Inquiry framework. In C. R. Payne (Ed.), Information technology and constructivism in higher education: Progressive learning frameworks (pp. 43-57). Hershey, PA: IGI Global. https://doi.org/10.4018/978-1-60566-654-9.ch004

Tanis, C. J. (2020). The seven principles of online learning: Feedback from faculty and alumni on its importance for teaching and learning. Research in Learning Technology, 28. https://doi.org/10.25304/rlt.v28.2319

Teng, D. C. E., Chen, N. S., Kinshuk, \& Leo, T. (2012). Exploring students' learning experience in an international online research seminar in the Synchronous Cyber Classroom. Computers \& Education, 58, 918-930. https://doi.org/10.1016/j.compedu.2011.10.018

Thompson, L., \& Ku, H. Y. (2010). Degree of online collaboration and team performance. A case study. Quarterly Review of Distance Education, 11(2), 127-134.

Tinto, V. (1997). Classrooms as communities. The Journal of Higher Education, 68(6), 599-623. https://doi.org/10.1080/00221546.1997.11779003

Wolcott, L. L. (1996). Distant, but not distanced: A learner-centered approach to distance education. TechTrends, 41(5), 23-27. https://doi.org/10.1007/BF02818902

Zheng, L. (2015). A systematic literature review of design-based research from 2004 to 2013. Journal of Computers in Education, 2(4), 399-420. https://doi.org/10.1007/s40692-015-0036-z

\section{Copyrights}

Copyright for this article is retained by the author(s), with first publication rights granted to the journal.

This is an open-access article distributed under the terms and conditions of the Creative Commons Attribution license which permits unrestricted use, distribution, and reproduction in any medium, provided the original work is properly cited. 